\title{
Uterine Fibroids (Leiomyomata) and Heavy Menstrual Bleeding
}

\author{
Outi Uimari ${ }^{1,2}$, Kavita S. Subramaniam ${ }^{3,4}$, Beverley Vollenhoven ${ }^{5,6}$ and \\ Thomas T. Tapmeier ${ }^{4,6 *}$ \\ ${ }^{1}$ Department of Obstetrics and Gynecology, Oulu University, Oulu, Finland, ${ }^{2}$ Research Unit for Pediatrics, Pediatric \\ Neurology, Pediatric Surgery, Child Psychiatry, Dermatology, Clinical Genetics, Obstetrics and Gynecology, \\ Otorhinolaryngology and Ophthalmology (PEDEGO) Research Unit and Medical Research Center Oulu, Oulu University \\ Hospital, Oulu, Finland, ${ }^{3}$ St John's Institute of Dermatology, King's College London, Guy's Hospital, London, \\ United Kingdom, ${ }^{4}$ Endometriosis CaRe Centre, Nuffield Department of Women's and Reproductive Health, University of \\ Oxford, Oxford, United Kingdom, ${ }^{5}$ Women's and Newborn Program, Monash Health, Clayton, VIC, Australia, ${ }^{6}$ Department of \\ Obstetrics and Gynaecology, Monash University, Clayton, VIC, Australia
}

OPEN ACCESS

Edited by:

Philippa Saunders,

University of Edinburgh,

United Kingdom

Reviewed by: Moamar Al-Jefout, United Arab Emirates University, United Arab Emirates Essam R. Othman, Assiut University, Egypt

*Correspondence:

Thomas T. Tapmeier thomas.tapmeier@monash.edu

Specialty section:

This article was submitted to Gynecology,

a section of the journal

Frontiers in Reproductive Health

Received: 19 November 2021 Accepted: 09 February 2022 Published: 04 March 2022

Citation:

Uimari O, Subramaniam KS, Vollenhoven B and Tapmeier TT (2022) Uterine Fibroids (Leiomyomata) and Heavy Menstrual Bleeding. Front. Reprod. Health 4:818243 doi: 10.3389/frph.2022.818243
Uterine Fibroids, or leiomyomata, affect millions of women world-wide, with a high incidence of $75 \%$ within women of reproductive age. In $\sim 30 \%$ of patients, uterine fibroids cause menorrhagia, or heavy menstrual bleeding, and more than half of the patients experience symptoms such as heavy menstrual bleeding, pelvic pain, or infertility. Treatment is symptomatic with limited options including hysterectomy as the most radical solution. The genetic foundations of uterine fibroid growth have been traced to somatic driver mutations (MED12, HMGA2, $\mathrm{FH}^{-1-}$, and COL4A5-A6). These also lead to downstream expression of angiogenic factors including IGF-1 and IGF-2, as opposed to the VEGF-driven mechanism found in the angiogenesis of hypoxic tumors. The resulting vasculature supplying the fibroid with nutrients and oxygen is highly irregular. Of particular interest is the formation of a pseudocapsule around intramural fibroids, a unique structure within tumor angiogenesis. These aberrations in vascular architecture and network could explain the heavy menstrual bleeding observed. However, other theories have been proposed such as venous trunks, or venous lakes caused by the blocking of normal blood flow by uterine fibroids, or the increased local action of vasoactive growth factors. Here, we review and discuss the evidence for the various hypotheses proposed.

Keywords: uterine fibroid, leiomyoma, heavy menstrual bleeding (HMB), somatic mutation, vascular architecture

\section{HEAVY MENSTRUAL BLEEDING AND UTERINE FIBROIDS}

As many as 1 in 20 women aged between 30 and 49 years consult their GP each year because of heavy menstrual bleeding ( $\mathrm{HMB}$ ) or menstrual problems, with menstrual disorders the reason for $12 \%$ of all referrals to gynecology services in the UK (1). While HMB was historically given as a blood loss of more than $80 \mathrm{~mL}$ per day (2) - a definition not considered useful any longer given the large variation in women's physique and the fact that most women who seek treatment for HMB do not actually meet this criterion (3) - HMB is now defined as "excessive menstrual blood loss which interferes with a woman's physical, social, emotional and/or material quality of life" (1). It can occur on its own or in combination with other symptoms such as acute and chronic pelvic pain, or infertility (4). The severity can be estimated by self-reporting in questionnaires (5). The potential causes for HMB are many, such as ovulatory disorders, adenomyosis, endometriosis, endometrial polyps, and endometrial hyperplasia (6); however, the most common condition underlying HMB are uterine fibroids. 
Uterine fibroids, or leiomyomata, are benign tumors of the myometrium arising within the uterus. Despite the name, fibroids largely comprise of myocytes rather than fibroblasts and are characterized by the excessive deposition of extracellular matrix substances, mainly collagen, within the tumor (7). The bulk growth of this extremely dense tissue leads an enlarged and deformed uterus and to some of the key symptoms associated with uterine fibroids in addition to HMB such as pressure symptoms, abdominal pain, and infertility $(4,6)$. In the United States, fibroids are cited to be the cause for over $50 \%$ of hysterectomies (8), and direct costs for their treatment is estimated between 4 and 9 billion USD (9).

Data on the incidence of uterine fibroids varies; while an Italian study of 341 non-care seeking women of reproductive age reported an incidence of $21.4 \%$ (10), a US study of 1,346 randomly selected women between 35 and 49 years screened by self-report, medical record and sonography, found an incidence of uterine fibroids by age 35 of $60 \%$ among African-American women, increasing to $>80 \%$ by age 50 , whereas Caucasian women in this study showed an incidence of $40 \%$ by age 35 , and almost $70 \%$ by age 50 (11). An online survey of 21,479 women from Brazil, Canada, France, Germany, Italy, South Korea, the UK and the US on the other hand found a self-reported incidence of $4.5-17.8 \%$ in women of reproductive age (12), indicating the importance of sample population, age bracket and genetic background to reported susceptibility. In up to $40 \%$ of patients, uterine fibroids cause HMB (13), and more than half of the patients experience combinations of symptoms such as HMB, pelvic pain, or infertility $(14,15)$.
Uterine fibroids are classified according to their location relative to the uterine anatomy in the FIGO system (16), but while intermenstrual bleeding as a symptom of uterine fibroids has been shown to correlate with the position and number of fibroids (13), the causal link to HMB is unknown. The classification of both HMB and the FIGO system are not without problems, as consistency between surgeons is lacking [Figure 1, (17)].

\section{CLINICAL CONSIDERATIONS AND TREATMENT OPTIONS}

With a comprehensive treatment plan lacking (6), current treatment of uterine fibroids largely provides symptomatic control. Treatment options are dictated by patient compliance, age, fertility preservation, and other common (co)morbidities such as endometriosis, adenomyosis, endometrial polyps, and endometrial hyperplasia that cause overlapping symptoms [pain and abnormal uterine bleeding (4)]. Follow-up evaluations of the tumor growth rate are recommended for asymptomatic fibroids by most evidence-based guidelines (18). Treatment options can be loosely classified by degree of invasiveness and the risk of reintervention (Table $\mathbf{1}$ ).

\section{MEDICAL MANAGEMENT}

Non-steroidal anti-inflammatory drugs (NSAID) reduce heavy menstrual bleeding (20). Although trials included in Cochrane meta-analyses commonly excluded UF and despite controversial evidence $(21,22)$, NSAIDs are recommended as an alternative

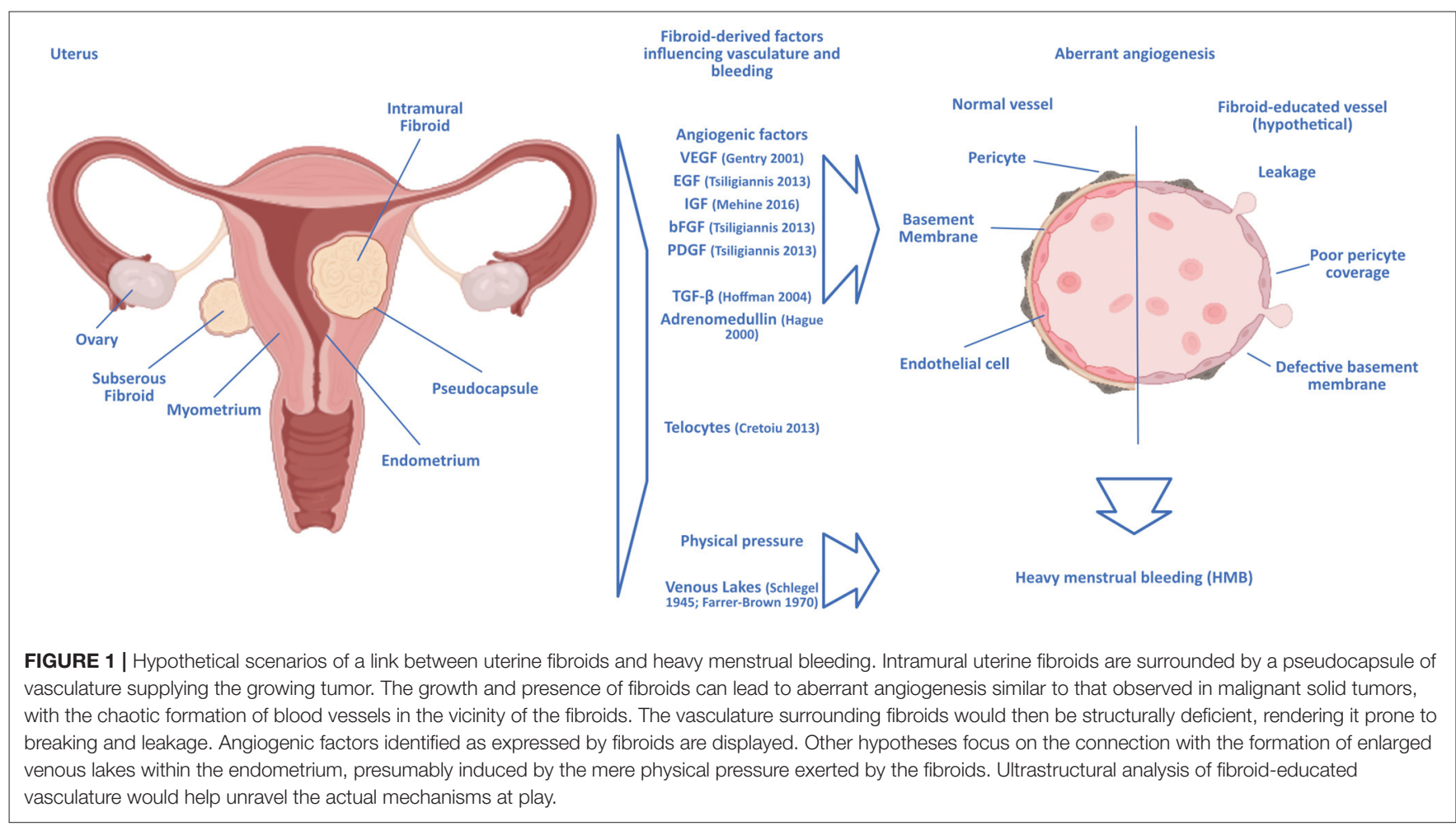


TABLE 1 | Comparison of treatment options for uterine fibroid-related heavy menstrual bleeding.

\begin{tabular}{|c|c|c|c|c|c|c|}
\hline Treatment & FIGO type (16) & Preserves fertility & Reversible & Additional outcome & Treatment course & $\begin{array}{r}\text { Reintervention rate } \\
\text { within } 5 \text { years (19) }\end{array}$ \\
\hline NSAID & $0-8$ & Yes & Yes & Pain relief & Long-term & $\mathrm{N} / \mathrm{A}$ \\
\hline TXA & $0-8$ & Yes & Yes & & Long-term & $\mathrm{N} / \mathrm{A}$ \\
\hline LNG-IUD & $2-8$ & Yes & Yes & Pain relief & Long-term & N/A \\
\hline $\mathrm{CHC}$ & $2-8$ & Yes & Yes & Pain relief & Long-term & $\mathrm{N} / \mathrm{A}$ \\
\hline $\begin{array}{l}\text { Progestin-only } \\
\text { contraceptive }\end{array}$ & $2-8$ & Yes & Yes & Pain relief & Long-term & $\mathrm{N} / \mathrm{A}$ \\
\hline UPA & $1-8$ & Yes & Yes & $\begin{array}{l}\text { Reduction of UF } \\
\text { volume }\end{array}$ & Short-term & $\mathrm{N} / \mathrm{A}$ \\
\hline $\mathrm{GnRH}$ agonist & $1-8$ & Yes & Yes & $\begin{array}{l}\text { Reduction of UF } \\
\text { volume }\end{array}$ & Short-term & $\mathrm{N} / \mathrm{A}$ \\
\hline GnRH antagonist & $1-8$ & Yes & Yes & $\begin{array}{l}\text { Reduction of UF } \\
\text { volume }\end{array}$ & Short-term & $\mathrm{N} / \mathrm{A}$ \\
\hline UAE & $1-6$ & Yes? & No & $\begin{array}{l}\text { Reduction of UF } \\
\text { volume }\end{array}$ & $\begin{array}{l}\text { One-time intervention } \\
\text { with long-term effects }\end{array}$ & $14.4 \%$ \\
\hline HIFU/MRgFUS & $2-8$ & Yes & No & $\begin{array}{l}\text { Reduction of UF } \\
\text { volume }\end{array}$ & $\begin{array}{l}\text { One-time intervention } \\
\text { with long-term effects }\end{array}$ & $53.9 \%$ \\
\hline $\begin{array}{l}\text { Hysteroscopic } \\
\text { myomectomy }\end{array}$ & $0-1 /(2)$ & Yes & No & $\begin{array}{l}\text { Removal of UF, } \\
\text { definitive treatment }\end{array}$ & $\begin{array}{l}\text { One-time intervention } \\
\text { with long-term effects }\end{array}$ & $7 \%$ \\
\hline $\begin{array}{l}\text { Laparoscopic/laparotomy } \\
\text { myomectomy }\end{array}$ & $3-8$ & Yes & No & $\begin{array}{l}\text { Removal of UF, } \\
\text { definitive treatment }\end{array}$ & $\begin{array}{l}\text { One-time intervention } \\
\text { with long-term effects }\end{array}$ & $12.2 \%$ \\
\hline Hysterectomy & $2-8$ & No & No & $\begin{array}{l}\text { Removal of uterus, } \\
\text { definitive treatment }\end{array}$ & $\begin{array}{l}\text { One-time intervention } \\
\text { with long-term effects }\end{array}$ & $0 \%$ \\
\hline
\end{tabular}

NSAID, non-steroidal anti-inflammatory drugs; LNG-IUD, levonorgestrel-releasing intrauterine devices; CHC, combined hormonal contraceptives; UPA, ulipristal acetate; GnRH, gonadotropin-releasing hormone; UAE, uterine artery embolization; HIFU/MRgFUS, high intensity focused ultrasound/magnetic resonance imaging-guided focused ultrasound; TXA, tranexamic acid (most evident contraindications are listed in the manuscript text).

option for levonorgestrel-releasing intrauterine devices (LNGIUD) to treat $\mathrm{HMB}$ in women with fibroids smaller than $3 \mathrm{~cm}$ in size (1). The antifibrinolytic agent, tranexamic acid preserves the fibrin matrix structure and is widely used to prevent and treat blood loss, and it has been shown to be effective in fibroidassociated HMB (23).

Intrauterine devices such as the $52 \mathrm{mg}$ LNG-IUD reduces menstrual bleeding in women with fibroids by inducing endometrial atrophy (24-26). The reduction in blood loss is significant, with evidence of successful treatment of anemia and increase in ferritin and hematocrit levels (27). However, the risk of expulsion for the device in a uterus with fibroids is increased compared to a non-fibroid uterus [11 vs. $0-3 \%$ (27)], with higher risks again for uteri with large and multiple fibroids. An additional limitation of studies published thus far is that they do not further explore those fibroid cases that fail in their aim to reduce HMB. There is no evidence yet on what type of fibroids LNG-IUD act on long-term, thus avoiding surgery, and for which subtypes other treatment options should be primarily considered. Many studies show a significant dropout rate of participants with no response to LNG-IUD, who require definitive treatment, i.e., a hysterectomy $(28,29)$. No data on the effectiveness of lower doses of levonorgestrel are yet available.

Combined hormonal and oral progestin-only contraceptives can be considered in the treatment of fibroid-associated HMB, although evidence is limited (30) and partly based on expert opinion (23). Again, these products can be an option for fibroids smaller than $3 \mathrm{~cm}$ in size (1).

Selective progesterone receptor modulators (SPRM) moderate progesterone activity (31). Ulipristal acetate (UPA) binds to the intracellular progesterone receptor and blocks the effects of progesterone; it is thus effective in reducing total fibroid and uterine volume but results in amenorrhea during treatment in most women (32). Several randomized clinical trials have been evaluated in a Cochrane Review, and according to moderatequality evidence, UPA improves the quality of life and reduces menstrual blood flow more than placebo and leuprolide (31). Similar results on quality of life, pain and bulk symptoms, efficacy and tolerability of UPA have been reported from RCTs in recent years (33-35). An exception are submucosal fibroids, which are less likely to respond with an improved bleeding pattern. Additionally, UPA improves the women's quality of life, and fibroid-related bulk and pain symptoms (36). It can be used preoperatively or as short-term management (usually as 3month intermittent courses). Due to cases of serious liver injury that an UPA product (Esmya) was suspected of causing, the European Medicines Agency (EMA) has recommended periodic liver monitoring before, during, and after treatment with UPA in all prospective patients, to minimize any risk of developing liver failure (37). More data on UPA vis-à-vis surgical treatment for $\mathrm{HMB}$ and fertility outcomes in uterine fibroids are expected in the near future as several new trial protocols have been published recently (clinicaltrials.gov). 
The anti-progestin mifepristone has been mainly studied and used for fibroid-associated HMB outside of Western countries. While its anti-glucocorticoid activity may limit its use, like UPA it decreases the size of fibroids, reduces heavy bleeding and improves pelvic pain symptoms and the quality of life, with spotting, elevations in liver enzymes, and endometrial hyperplasia reported as side effects $(38,39)$.

The estrogen receptor ligands raloxifene and tamoxifen act as selective estrogen receptor modulators (SERM). Their effect on fibroid size and associated symptoms have been investigated, but without significant evidence of alleviation of HMB (23).

Gonadotropin-releasing hormone (GnRH) agonists initially stimulate the pituitary gland and ovaries, then cause downregulation of GnRH receptors with full suppression of estradiol, causing a hypoestrogenic state. Via this mechanism they induce amenorrhea and reduce UF and uterine volume significantly but cause menopausal symptoms and bone loss (6). Due to these side effects, GnRH agonists are primarily used as short-course treatment (2-6 months) preoperatively to improve the effects of more conservative and less invasive surgical techniques (40).

$\mathrm{GnRH}$ antagonists competitively inhibit $\mathrm{GnRH}$ receptors in the pituitary gland and reduce circulating gonadotropins and ovarian sex hormones, including estradiol. Two oral GnRH antagonists with hormonal add-back therapies (indicated to offset hypoestrogenic effects including hot flushes, adverse lipid metabolism, and bone loss), elagolix and relugolix can be considered for the treatment of fibroid-associated HMB (4143). Both have proven effective in reducing fibroid-associated $\mathrm{HMB}$, and relugolix additionally seems to improve pain and bulk symptoms (43). In 2020, the U.S. Food and Drug Administration (FDA) approved the combination of elagolix (300 $\mathrm{mg}$ twice daily) with add-back therapy ( $1 \mathrm{mg}$ estradiol and $0.5 \mathrm{mg}$ norethindrone acetate once daily) to be used for up to 24 months (44). Relugolix (40 mg once daily) with add-back therapy ( $1 \mathrm{mg}$ estradiol and $0.5 \mathrm{mg}$ norethisterone acetate) was approved by the European Commission in July 2021 (45), and in October 2021 the agent was granted a license by the UK's Medicines and Healthcare Products Regulatory Agency (MHRA) (46).

\section{RADIOLOGICAL MANAGEMENT}

Uterine artery embolization (UAE) can be recommended as a minimally invasive treatment for fibroid-associated bleeding and bulk symptoms in women who desire to preserve their uterus (47). An embolic agent is delivered through catherization of both uterine arteries to cause devascularization and involution of uterine fibroids. After UAE, significant reductions in fibroid and uterine volumes have been observed, which were maintained for up to 5 years (23). The bleeding pattern is usually improved following embolization, and the quality of life 2-5 years after treatment is similar among patients undergoing UAE, hysterectomy, or myomectomy (48). Although the surgical reintervention rate for UAE is higher than that for myomectomy [ 14.4 vs. $12.2 \%$ at 60 months (19)], rates for major post-procedural complications are lower in comparison to any type of surgery for uterine fibroids $(19,49)$.
Focused ultrasound procedures guided by diagnostic ultrasound (high intensity focused ultrasound, HIFU) or magnetic resonance imaging (Magnetic Resonance-guided Focused Ultrasound, MRgFUS), are non-invasive treatments using multiple high-intensity ultrasound waves to cause coagulative necrosis within fibroids (50). According to the limited published data, HIFU and MRgFUS reduce both fibroid and uterine volume (23) and improve the quality of life-but the evidence is of low quality (51). The rate of reintervention after HIFU is estimated to be as high as $53.9 \%$ at 60 months (19).

Radiofrequency ablation (RFA) of fibroids is a minimally invasive procedure that uses heat generated through radiofrequency waves with ultrasound guidance to induce coagulative necrosis in targeted fibroids to reduce their size. RFA can be delivered via a laparoscopic, transvaginal, or transcervical approach depending on fibroid location. UF volume reductions have ranged from 32 to $66 \%$ at 12 months of follow-up, and at $77 \%$ at later time points. RFA improves UF associated symptoms and quality of life. Surgical reintervention rate at 3 years is $11.5 \%$ (50). While RFA thus seems to be a good management option for symptomatic fibroids, access to this procedure is currently very limited. Both of these methods rely on adequate imaging to guide treatment.

\section{SURGICAL MANAGEMENT}

Endometrial ablation is a procedure performed via hysteroscopy that surgically destroys a layer of endometrium to reduce menstrual bleeding. Current evidence is insufficient to assess the effectiveness of this management option to improve fibroid symptoms (23).

Myomectomy describes the surgical removal of fibroid tissue either via hysteroscopy, laparoscopy, laparotomy, minilaparotomy, or laparoscopically-assisted minilaparotomy. Hysteroscopic myomectomy is the primary management option for $\mathrm{HMB}$ from submucosal (FIGO type 0) and partly submucosal fibroids (FIGO type $1, \geq 50 \%$ of the fibroid situated within the uterine cavity). Myomectomy can also be considered for FIGO type 2 fibroids (partly submucosal fibroid with $\geq 50 \%$ in an intramural location), albeit with a higher risk for repeated surgery or further need of medical management. Hysteroscopic myomectomy significantly improves fibroidassociated symptoms and quality of life, and the reintervention rate is as low as $7 \%$ at 5 years (19). Myomectomy via laparoscopy or laparotomy are a second-line treatment for FIGO type 3-8 fibroids if medication has failed $(6,50)$. Improvements in the quality of life are similar regardless of surgery type, but laparosopic myomectomy is associated with faster recovery time (50). The surgical reintervention rate for laparoscopic and laparotomy myomectomy is $12.2 \%$ (19).

The definitive surgical management for the treatment of fibroid-associated $\mathrm{HMB}$, pain and pressure symptoms is hysterectomy. It is suitable for women who do not desire future pregnancies or do not wish to retain their uterus. Hysterectomy substantially improves hemoglobin levels and anemia, bulk symptoms (23, 52, 53) and the 
women's quality of life (54). However, blood transfusions following intraoperative hemorrhage, thromboembolism, and intraoperative bowel/bladder/ureter injury are apparent risks (23). The size and shape of the uterus (deformed by fibroids) directs the chosen hysterectomy route (vaginal, laparoscopic, and laparotomy).

The analysis of data from uterine fibroid registries such as COMPARE-UF in the United States could provide comparative effectiveness data regarding treatment options in the future (55).

\section{ANGIOGENESIS IN UTERINE FIBROIDS}

Hardly any tissue in the human body undergoes angiogenesis to the degree and frequency as the endometrium, where angiogenesis is vital during the growth of the endometrium in the proliferative phase of the menstrual cycle, the build-up and elongation of spiral arteries in the secretory phase, and the repairs during and after menstruation (56). In the neighboring myometrium, angiogenesis has been shown to be influenced by the presence of uterine fibroids through an increased proliferative response to estrogen and progesterone in smooth muscle cells in the presence of fibroids compared to normal myometrium [Figure 1, (57)].

An array of angiogenic factors involved in the vascularization and growth of uterine fibroids has been identified, including epidermal growth factor (EGF), heparin-binding-EGF, vascular endothelial growth factor (VEGF), insulin-like growth factor (IGF), basic fibroblast growth factor (bFGF), platelet derived growth factor (PDGF), transforming growth factor- $\beta$ (TGF$\beta$ ), and adrenomedullin (58). Driver mutations within uterine fibroids have been elucidated in the past two decades as a mutated Mediator Complex subunit 12 (MED12), mutations in the gene encoding the DNA-binding high mobility group AT-hook 2 (HMGA2), fumarate hydratase (FH) deficiency, and mutations in the genes encoding the collagen type IV $\alpha 5$ chain/collagen type IV $\alpha 6$ chains (Col4A5/A6) (59). Interestingly, 65\% of tumors show mutations in the MED12 gene (60), and another 25\% show aberrations in HMGA2-driven gene expression $(15,61)$. Uterine fibroids arising from these two mutations show different characteristics; with fibroids driven by MED12 mutations more numerous but smaller in size (62) compared to fibroids driven by HMGA2 (63). MED12 has been shown to alter WNT/ $\beta$ catenin pathway expression (64). In a mouse model of uterine fibroids, this resulted in a breakdown of cytoplasmic and an increase in nuclear levels of $\beta$-catenin, associated with an increased fibroid burden (65). Knockdown of the MED12 gene on the other hand resulted in decreased proliferation of fibroid cells as induced by the WNT/ $\beta$-catenin pathway, and thus decreased fibroid growth (66). Apart from growth-promoting effects, these mutations increase the expression of downstream targets including angiogenic factors, most notably the insulin-like growth factor (IGF) system (59). The factors of the IGF family and their binding proteins (IGFBPs) have been shown to regulate tube formation and cell migration in endothelial cells (67), and could explain the formation of blood vessels around the uterine fibroids in the absence of HIF-1 $\alpha$ /VEGF signaling.
The role of vascular endothelial growth factor (VEGF) has been studied in detail following its discovery in 1989 (68), and it has become one of the most important targets in antiangiogenic tumor therapy (69). In uterine fibroids, VEGF levels have been reported as either similar (70) or increased (71) in fibroid tissues vs. adjacent myometrium, with an observation of declining VEGF levels after hysterectomy (72). Compared to myometrium, the expression of EGF was also reported to be higher in fibroid tissue (73), as did FGF (73), PDGF (73), TGF$\beta$ (74), IGF-1 (75), and adrenomedullin (76). An indication that angiogenesis in uterine fibroids could follow a different trajectory from the normal hypoxia response-with HIF-1 $\alpha$ stabilization and the expression of VEGF as a result, which in turn induces sprouting and outgrowth of endothelial cells nearby to establish a connection to vascular supply (77) - was the finding that despite their hypoxic state, uterine fibroids surprisingly show a downregulation of key players of the normal hypoxic response, HIF- $1 \alpha$ for example has been shown lacking in uterine fibroids, when it was readily shown in leiomyosarcomata $(78,79)$. Aberrant vasculature as seen in tumors shows a chaotic structure and is prone to leaking; thus, alternative angiogenesis mechanisms, e.g., primarily through IGF signaling, might explain the HMB seen in women with uterine fibroids (80).

\section{PSEUDOCAPSULE}

While the fibroid mass itself is poorly vascularised, it can be surrounded by a highly vascularised pseudocapsule in intramural fibroids, a specialized layer of tissue between the tumor and the surrounding myometrium that contains the blood vessels needed to sustain the fibroid (81), which develops in response to the fibroid growth (82). This structure can be seen as a "ring of fire" in ultrasound Doppler imaging, and it is separated from the myometrium by a clear cleft, as observed in histological images. The bursting of the vessels contained within the pseudocapsule could explain the HMB observed in women with uterine fibroids, in which case the symptom should correlate with the position of the fibroids, as the pseudocapsule only develops around intramural fibroids; this seems to be the case (13). The pseudocapsule is made up of the same cell types and shows the same biologic structure as the neighboring myometrium (83); however, the vasculature of the pseudocapsule might harbor structural defects that rend it susceptible to breaking, leading to HMB.

Responsible could be "telocytes," a comparably recent discovery in the interstitial myometrium $\left(\mathrm{CD} 34^{+} \mathrm{c}\right.$ $\mathrm{kit}^{+}$PDGFR $\left.\alpha^{+}\right)$. Telocytes have elongated telopodes, podomers, and regional podoms that stretch into the surrounding tissue; the cells thus stay in physical contact with many other cell types (84). In the uterus, telocytes are in especially close contact with smooth muscle cells (85) and are speculated to coordinate myometric contractions. Telocytes in the uterus express estrogen and progesterone receptors and are thought capable of regulating smooth muscle cell proliferation (84). Intriguingly, telocytes are not present within uterine fibroids but are found within 
surrounding myometrium (86). They express VEGF and could thus contribute to angiogenesis in the pseudocapsule.

\section{VENOUS LAKES}

An older, classic theory of how HMB is connected to uterine fibroids suggests that "venous lakes" are responsible for the increased bleeding during menstruation: These large sinusoidal structures have long been known to form physiologically within the uterine vasculature from arteriovenous anastomoses (87). The blood flow into the venous lakes was thought to lead to a loss of pressure in the capillary system supporting the buildup of endometrium until the increase in venous lakes and the limited potential for increasing the supply pressure meant that the endometrium would die off, thus starting menstruation. Because the venous lakes lack any closing mechanism, they would bleed until completely sloughed off, and the menstrual loss of endometrium would only stop once the basal layer, supported by capillaries but without any arteriovenous anastomoses, had been reached. Microradiographic studies in the 1970's supported the notion that HMB resulted not from the fibroid vasculature itself but rather from venous lakes dilated and enlarged by virtue of increased interstitial pressure from the growing tumors (88). Once corrosion cast microscopy methods became available, studies into vascular changes within the myometrium in the presence of uterine fibroids indeed found venous lakes enlarged in uteri bearing fibroids in comparison to normal uteri (89), and further support to the theory was lent by immunohistochemistry studies of cyclic changes in uterine vasculature showing dilated and disintegrating venous vessels in the upper functionalis layer of the endometrium (90), showing that menstrual blood was largely venous in origin. However, the notion that physical pressure was the main factor leading to enlarged venous lakes was challenged once molecular biological analyses of angiogenic factors were able to show that indeed growth factors were largely responsible for the enlargement of veins and venous lakes (91), and that the heavy bleeding resulted from a failure of the fibrin/platelet plugs formed in the coagulation cascade in closing these blood vessels of increased diameter successfully.

\section{VASCULAR ARCHITECTURE, ABERRATIONS}

The decisive factor could be the aberrant architecture of the fibroid-educated vasculature. Vasculature growing rapidly around malignant tumors in response to hypoxia is highly irregular, with high tortuosity, shunting of vessels and non-patent ends. Instead of ordered layers of pericytes and $\alpha$-smooth muscle actin, tumor vasculature lacks stabilization through pericytes, and the $\alpha$-smooth muscle actin is merely sporadically wrapped around the vessels (92). This renders tumor vasculature leaky and prone to breaking, enables the intravasation of metastatic tumor cells and hinders the successful delivery of drugs to the tumor (93). The vasculature developing around uterine fibroids could similarly show structural defects; however, elucidating these requires microscopy-driven avenues of investigation rather than omics approaches, as the latter would not necessarily flag any difference in vascular architecture as long as the quantities of the building blocks are not altered significantly. If proven to be similarly defective, the architecture of fibroideducated vasculature could be targeted in analogy to the vascular normalization angle in tumor therapies (94).

\section{PHYSICAL MECHANISMS}

Fibroids may cause HMB merely physically, i.e., through an increase in endometrial surface due to underlying fibroid growth; through an influence on normal myometrial contractility patterns; through an ulcerated or degenerating fibroid, or through uterine venous ectasia due to compression from the fibroids (95). Fibroids were shown to secrete increased levels of transforming factor-beta 3 (TGF- $\beta 3$ ) in response to steroids, as the estrogen and progesterone native to the uterus (96). TGF- $\beta$ is associated with fibrotic disease, such as renal (97) or pulmonary fibrosis (98), where it induces the emergence of collagen-producing myofibroblasts via an epithelial-mesenchymal transition (EMT) (97). Although distinct from fibrotic disease, a role of TGF- $\beta$ in uterine fibroids may enhance our understanding of the pathomechanism leading to HMB. TGF- $\beta 3$ secreted by fibroids has been shown to induce BMP-2 resistance in endometrium by down-regulation of BMPR2, likely causing defective endometrial decidualization (99). TGF$\beta 3$ also reduces expression of plasminogen activator inhibitor1 (PAI-1), Antithrombin III (ATIII), and thrombomodulin in endometrium, likely contributing to bleeding (99). Interestingly, seasonally different patterns of circulating levels of interleukins (IL)-10, IL-13, and IL-17-all associated with fibrotic diseasehave been identified in women with fibroids, similarly pointing toward an involvement of the wound healing immune response in fibroid growth and possibly HMB (100).

\section{CONCLUSION}

Uterine fibroids are one of the main indications for heavy menstrual bleeding, a symptom that causes considerable impairment to patients' quality of life. Apart from hysterectomy, none of the currently available treatment options addresses this problem satisfactorily, a conundrum underlined by the fact that many women require definitive surgical management after exhausting their medical management options. Treatment options that would go beyond the merely symptomatic will depend on further knowledge of the influence of uterine fibroids on blood vessel growth and structure. The somatic mutations giving rise to uterine fibroids hold some clues as to their angiogenic potential, but the causal link between uterine fibroids and heavy menstrual bleeding is not yet known. While several hypotheses have been proposed during the last decades, structural studies of the vascular architecture of the blood vessels supplying uterine fibroids and the specific angiogenesis mechanisms that lead to their growth are needed to unravel the causal link between uterine fibroids and heavy menstrual bleeding, and thus enable the search for better therapies. 


\section{AUTHOR CONTRIBUTIONS}

TT and OU conceived of the idea. OU, KS, BV, and TT wrote and discussed the manuscript. All authors agreed to the final version.

\section{REFERENCES}

1. National Institute for Health and Care Excellence. Heavy Menstrual Bleeding: Assessment and Management. London: National Institute for Health and Care Excellence (2018).

2. Hallberg L, Högdahl A-M, Nilsson L, Rybo G. Menstrual blood loss-a population study: variation at different ages and attempts to define normality. Acta Obstet Gynecol Scand. (1966) 45:320-51. doi: 10.3109/00016346609158455

3. Warner PE, Critchley HO, Lumsden MA, Campbell-Brown M, Douglas A, Murray GD. Menorrhagia II: is the $80-\mathrm{mL}$ blood loss criterion useful in management of complaint of menorrhagia? Am J Obstet Gynecol. (2004) 190:1224-9. doi: 10.1016/j.ajog.2003.11.016

4. Uimari O, Nazri H, Tapmeier T. Endometriosis and uterine fibroids (leiomyomata): comorbidity, risks and implications. Front Reprod Heal. (2021) 3:18. doi: 10.3389/frph.2021.750018

5. Tapmeier TT, Nazri HM, Subramaniam KS, Manek S, Garbutt K, Flint EJ, et al. Protocol for a longitudinal, prospective cohort study investigating the biology of uterine fibroids and endometriosis, and patients' quality of life: the FENOX study. BMJ Open. (2020) 10:e032220. doi: 10.1136/bmjopen-2019-032220

6. Stewart EA, Laughlin-Tommaso SK, Catherino WH, Lalitkumar S, Gupta D, Vollenhoven B. Uterine fibroids. Nat Rev Dis Prim. (2016) 2:16043. doi: $10.1038 / \mathrm{nrdp} .2016 .43$

7. Holdsworth-Carson SJ, Zhao D, Cann L, Bittinger S, Nowell CJ, Rogers PAW. Differences in the cellular composition of small vs. large uterine fibroids. Reproduction. (2016) 152:467-80. doi: 10.1530/REP-16-0216

8. Aarts JW, Nieboer TE, Johnson N, Tavender E, Garry R, Mol BWJ, et al. Surgical approach to hysterectomy for benign gynaecological disease. Cochrane Database Syst. Rev. (2015) 2015:CD003677. doi: 10.1002/14651858.CD003677.pub5

9. Cardozo ER, Clark AD, Banks NK, Henne MB, Stegmann BJ, Segars JH. The estimated annual cost of uterine leiomyomata in the United States. Am J Obstet Gynecol. (2012) 206:211.e1-9. doi: 10.1016/j.ajog.2011.12.002

10. Marino JL, Eskenazi B, Warner M, Samuels S, Vercellini P, Gavoni $\mathrm{N}$, et al. Uterine leiomyoma and menstrual cycle characteristics in a population-based cohort study. Hum Reprod. (2004) 19:2350-5. doi: 10.1093/humrep/deh407

11. Day Baird D, Dunson DB, Hill MC, Cousins D, Schectman JM. High cumulative incidence of uterine leiomyoma in black and white women: ultrasound evidence. Am J Obstet Gynecol. (2003) 188:1007. doi: $10.1067 / \mathrm{mob} .2003 .99$

12. Zimmermann A, Bernuit D, Gerlinger C, Schaefers M, Geppert K. Prevalence, symptoms and management of uterine fibroids: an international internet-based survey of 21,746 women. BMC Womens Health. (2012) 12:6. doi: $10.1186 / 1472-6874-12-6$

13. Foth D, Röhl F-W, Friedrich C, Tylkoski H, Rabe T, Römer T, et al. Symptoms of uterine myomas: data of an epidemiological study in Germany. Arch Gynecol Obstet. (2017) 295:415-26. doi: 10.1007/s00404-0164239-y

14. Gupta S, Jose J, Manyonda I. Clinical presentation of fibroids. Best Pract Res Clin Obstet Gynaecol. (2008) 22:615-26. doi: 10.1016/j.bpobgyn.2008.01.008

15. Longo DL, Bulun SE. Uterine fibroids. N Engl J Med. (2013) 369:134455. doi: 10.1056/NEJMra1209993

16. Munro MG, Critchley HOD, Fraser IS. The two FIGO systems for normal and abnormal uterine bleeding symptoms and classification of causes of abnormal uterine bleeding in the reproductive years: 2018 revisions. Int $J$ Gynecol Obstet. (2018) 143:393-408. doi: 10.1002/ijgo.12666

17. Laughlin-Tommaso SK, Borah BJ, Stewart EA. Effect of menses on standardized assessment of sexual dysfunction among women

\section{ACKNOWLEDGMENTS}

The figure was created with help from

Biorender (www.biorender.org). with uterine fibroids: a cohort study. Fertil Steril. (2015) 104:435-9. doi: 10.1016/j.fertnstert.2015.04.029

18. Amoah A, Joseph N, Reap S, Quinn S. Appraisal of national and international uterine fibroid management guidelines: a systematic review. BJOG Int J Obstet Gynaecol. (2021) 129, 356-64. doi: 10.22541/au.161907774.45454712/v1

19. Sandberg EM, Tummers FHMP, Cohen SL, van den Haak L, Dekkers OM, Jansen FW. Reintervention risk and quality of life outcomes after uterinesparing interventions for fibroids: a systematic review and meta-analysis. Fertil Steril. (2018) 109:698-707.e1. doi: 10.1016/j.fertnstert.2017.11.033

20. Bofill Rodriguez M, Lethaby A, Farquhar C. Non-steroidal antiinflammatory drugs for heavy menstrual bleeding. Cochrane Database Syst Rev. (2019) 9:CD000400. doi: 10.1002/14651858.CD000400.pub4

21. Mäkäräinen L, Ylikorkala O. Primary and myoma-associated menorrhagia: role of prostaglandins and effects of ibuprofen. Br J Obstet Gynaecol. (1986) 93:974-8. doi: 10.1111/j.1471-0528.1986.tb08019.x

22. Ylikorkala O, Pekonen F. Naproxen reduces idiopathic but not fibromyomainduced menorrhagia. Obstet Gynecol. (1986) 68:10-2.

23. Hartmann KE, Fonnesbeck C, Surawicz T, Krishnaswami S, Andrews JC, Wilson JE, et al. Management of Uterine Fibroids. Comparative Effectiveness Review No. 195. Rockville, MD: Agency for Healthcare Research and Quality (2017).

24. Grigorieva V. Use of a levonorgestrel-releasing intrauterine system to treat bleeding related to uterine leiomyomas. Fertil Steril. (2003) 79:11948. doi: 10.1016/S0015-0282(03)00175-4

25. Sangkomkamhang US, Lumbiganon $\mathrm{P}$, Laopaiboon M, Mol BWJ. Progestogens or progestogen-releasing intrauterine systems for uterine fibroids. Cochrane Database Syst. Rev. (2013) 2013:CD008994. doi: 10.1002/14651858.CD008994.pub2

26. Bofill Rodriguez M, Lethaby A, Jordan V. Progestogen-releasing intrauterine systems for heavy menstrual bleeding. Cochrane Database Syst Rev. (2020) 2020:CD002126. doi: 10.1002/14651858.CD002126.pub4

27. Zapata LB, Whiteman MK, Tepper NK, Jamieson DJ, Marchbanks $\mathrm{PA}$, Curtis KM. Intrauterine device use among women with uterine fibroids: a systematic review. Contraception. (2010) 82:41-55. doi: 10.1016/j.contraception.2010.02.011

28. Kriplani A, Awasthi D, Kulshrestha V, Agarwal N. Efficacy of the levonorgestrel-releasing intrauterine system in uterine leiomyoma. Int $J$ Gynecol Obstet. (2012) 116:35-8. doi: 10.1016/j.ijgo.2011.07.031

29. Senol T, Kahramanoglu I, Dogan Y, Baktiroglu M, Karateke A, Suer N. Levonorgestrel-releasing intrauterine device use as an alternative to surgical therapy for uterine leiomyoma. Clin Exp Obstet Gynecol. (2015) 42:224-7. doi: $10.12891 / \operatorname{ceog} 1826.2015$

30. Marret H, Fritel X, Ouldamer L, Bendifallah S, Brun J-L, De Jesus I, et al. Therapeutic management of uterine fibroid tumors: updated French guidelines. Eur J Obstet Gynecol Reprod Biol. (2012) 165:15664. doi: 10.1016/j.ejogrb.2012.07.030

31. Murji A, Whitaker L, Chow TL, Sobel ML. Selective progesterone receptor modulators (SPRMs) for uterine fibroids. Cochrane Database Syst Rev. (2017) 2017:CD010770. doi: 10.1002/14651858.CD010770.pub2

32. Donnez J, Vázquez F, Tomaszewski J, Nouri K, Bouchard P, Fauser $\mathrm{BCJM}$, et al. Long-term treatment of uterine fibroids with ulipristal acetate. Fertil Steril. (2014) 101:1565-73.e18. doi: 10.1016/j.fertnstert.2014. 02.008

33. Liu JH, Soper D, Lukes A, Gee P, Kimble T, Kroll R, et al. Ulipristal acetate for treatment of uterine leiomyomas. Obstet Gynecol. (2018) 132:124151. doi: 10.1097/AOG.0000000000002942

34. Simon JA, Catherino W, Segars JH, Blakesley RE, Chan A, Sniukiene V, et al. Ulipristal acetate for treatment of symptomatic uterine leiomyomas. Obstet Gynecol. (2018) 131:431-9. doi: 10.1097/AOG.0000000000002462 
35. Lukes AS, Soper D, Harrington A, Sniukiene V, Mo Y, Gillard $\mathrm{P}$, et al. Health-related quality of life with ulipristal acetate for treatment of uterine leiomyomas. Obstet Gynecol. (2019) 133:869-78. doi: 10.1097/AOG.0000000000003211

36. Donnez J, Courtoy GE, Donnez O, Dolmans M-M. Ulipristal acetate for the management of large uterine fibroids associated with heavy bleeding: a review. Reprod Biomed Online. (2018) 37:216-23. doi: 10.1016/j.rbmo.2018.04.040

37. Donnez J, Arriagada P, Marciniak M, Larrey D. Liver safety parameters of ulipristal acetate for the treatment of uterine fibroids: a comprehensive review of the clinical development program. Expert Opin Drug Saf. (2018) 17:1225-32. doi: 10.1080/14740338.2018.1550070

38. Esteve JLC, Acosta R, Pérez Y, Campos R, Hernández AV, Texidó CS. Treatment of uterine myoma with 5 or $10 \mathrm{mg}$ mifepristone daily during 6 months, post-treatment evolution over 12 months: double-blind randomised clinical trial. Eur J Obstet Gynecol Reprod Biol. (2012) 161:2028. doi: 10.1016/j.ejogrb.2011.12.018

39. Tristan M, Orozco LJ, Steed A, Ramirez-Morera A, Stone P. Mifepristone for uterine fibroids. Cochrane Database Syst Rev. (2012) 2021:CD007687. doi: 10.1002/14651858.CD007687.pub2

40. Stewart EA. Uterine fibroids. N Engl J Med. (2015) 372:164655. doi: 10.1056/NEJMcp1411029

41. Schlaff WD, Ackerman RT, Al-Hendy A, Archer DF, Barnhart KT, Bradley $\mathrm{LD}$, et al. Elagolix for heavy menstrual bleeding in women with uterine fibroids. N Engl J Med. (2020) 382:328-40. doi: 10.1056/NEJMoa1904351

42. Simon JA, Al-Hendy A, Archer DF, Barnhart KT, Bradley LD, Carr $\mathrm{BR}$, et al. Elagolix treatment for up to 12 months in women with heavy menstrual bleeding and uterine leiomyomas. Obstet Gynecol. (2020) 135:1313-26. doi: 10.1097/AOG.0000000000003869

43. Al-Hendy A, Lukes AS, Poindexter AN, Venturella R, Villarroel C, Critchley HOD, et al. Treatment of uterine fibroid symptoms with relugolix combination therapy. $N$ Engl J Med. (2021) 384:630-42. doi: 10.1056/NEJMoa2008283

44. AbbVie Inc. OriahnnTM (Elagolix, Estradiol, and Norethindrone Acetate Capsules Elagolix Capsules). Highlights of Prescribing Information. Chicago. (2020). Available online at: https://www.rxabbvie.com/pdf/oriahnn_pi.pdf (accessed January 12, 2022).

45. European Commission. Union Register of Medicinal Products. (2021). Available online at: https://ec.europa.eu/health/documents/communityregister/html/h1565.htm (accessed January 12, 2022).

46. NICE. Relugolix With Oestradiol and Norethisterone Acetate for Treating Uterine Fibroids [ID3842]. Dev. (2021). Available online at: https://www.nice. org.uk/guidance/indevelopment/gid-ta10734 (accessed November 11, 2021).

47. Torre A, Paillusson B, Fain V, Labauge P, Pelage JP, Fauconnier A. Uterine artery embolization for severe symptomatic fibroids: effects on fertility and symptoms. Hum Reprod. (2014) 29:490-501. doi: 10.1093/humrep/det459

48. Gupta JK, Sinha A, Lumsden MA, Hickey M. Uterine artery embolization for symptomatic uterine fibroids. Cochrane Database Syst Rev. (2014) 2014:CD005073. doi: 10.1002/14651858.CD005073.pub4

49. Edwards RD, Moss JG, Lumsden MA, Wu O, Murray LS, Twaddle $S$, et al. Uterine-artery embolization versus surgery for symptomatic uterine fibroids. $N$ Engl J Med. (2007) 356:360-70. doi: 10.1056/NE JMoa062003

50. American College of Obstetricians and Gynecologists' Committee on Practice Bulletins-Gynecology. Management of symptomatic uterine leiomyomas. Obstet Gynecol. (2021) 137:e100-15. doi: 10.1097/AOG.0000000000004401

51. Chen J, Li Y, Wang Z, McCulloch P, Hu L, Chen W, et al. Evaluation of high-intensity focused ultrasound ablation for uterine fibroids: an IDEAL prospective exploration study. BJOG Int J Obstet Gynaecol. (2018) 125:35464. doi: 10.1111/1471-0528.14689

52. Volkers NA, Hehenkamp WJK, Birnie E, Ankum WM, Reekers JA. Uterine artery embolization versus hysterectomy in the treatment of symptomatic uterine fibroids: 2 years' outcome from the randomized EMMY trial. Am J Obstet Gynecol. (2007) 196:519.e1-11. doi: 10.1016/j.ajog.2007. 02.029

53. Ruuskanen A, Hippeläinen M, Sipola P, Manninen H. Uterine artery embolisation versus hysterectomy for leiomyomas: primary and 2-year follow-up results of a randomised prospective clinical trial. Eur Radiol. (2010) 20:2524-32. doi: 10.1007/s00330-010-1829-0

54. Hehenkamp WJK, Volkers NA, Birnie E, Reekers JA, Ankum WM. Symptomatic uterine fibroids: treatment with uterine artery embolization or hysterectomy-results from the randomized clinical embolisation versus hysterectomy (EMMY) trial. Radiology. (2008) 246:823-32. doi: 10.1148/radiol.2463070260

55. Stewart EA, Lytle BL, Thomas L, Wegienka GR, Jacoby V, Diamond MP, et al. The Comparing Options for Management: PAtient-centered REsults for Uterine Fibroids (COMPARE-UF) registry: rationale and design. Am J Obstet Gynecol. (2018) 219:95.e1-10. doi: 10.1016/j.ajog.2018.05.004

56. Gargett C, Rogers P. Human endometrial angiogenesis. Reproduction. (2001) 121:181-6. doi: 10.1530/rep,.0.1210181

57. Fleischer R, Weston GC, Vollenhoven BJ, Rogers PAW. Pathophysiology of fibroid disease: angiogenesis and regulation of smooth muscle proliferation. Best Pract Res Clin Obstet Gynaecol. (2008) 22:60314. doi: 10.1016/j.bpobgyn.2008.01.005

58. Tal R, Segars JH. The role of angiogenic factors in fibroid pathogenesis: potential implications for future therapy. Hum Reprod Update. (2014) 20:194-216. doi: 10.1093/humupd/dmt042

59. Mehine M, Kaasinen E, Heinonen H-R, Mäkinen N, Kämpjärvi K, Sarvilinna $\mathrm{N}$, et al. Integrated data analysis reveals uterine leiomyoma subtypes with distinct driver pathways and biomarkers. Proc Natl Acad Sci USA. (2016) 113:1315-20. doi: 10.1073/pnas.1518752113

60. Mäkinen N, Mehine M, Tolvanen J, Kaasinen E, Li Y, Lehtonen HJ, et al. MED12, the mediator complex subunit 12 gene, is mutated at high frequency in uterine leiomyomas. Science. (2011) 334:2525. doi: $10.1126 /$ science. 1208930

61. Mehine M, Kaasinen E, Mäkinen N, Katainen R, Kämpjärvi K, Pitkänen E, et al. Characterization of uterine leiomyomas by whole-genome sequencing. $N$ Engl J Med. (2013) 369:43-53. doi: 10.1056/NEJMoa1302736

62. Ferrero H. HMGA2 involvement in uterine leiomyomas development through angiogenesis activation. Fertil Steril. (2020) 114:974-5. doi: 10.1016/j.fertnstert.2020.07.044

63. Li Y, Qiang W, Griffin BB, Gao T, Chakravarti D, Bulun S, et al. HMGA2mediated tumorigenesis through angiogenesis in leiomyoma. Fertil Steril. (2020) 114:1085-96. doi: 10.1016/j.fertnstert.2020.05.036

64. Mosimann C, Hausmann G, Basler K. $\beta$-Catenin hits chromatin: regulation of Wnt target gene activation. Nat Rev Mol Cell Biol. (2009) 10:27686. doi: $10.1038 / \mathrm{nrm} 2654$

65. Tanwar PS, Lee H-J, Zhang L, Zukerberg LR, Taketo MM, Rueda BR, et al. Constitutive activation of beta-catenin in uterine stroma and smooth muscle leads to the development of mesenchymal tumors in mice. Biol Reprod. (2009) 81:545-52. doi: 10.1095/biolreprod.108.075648

66. Al-Hendy A, Laknaur A, Diamond MP, Ismail N, Boyer TG, Halder SK. Silencing Med12 gene reduces proliferation of human leiomyoma cells mediated via Wnt/ $\beta$-catenin signaling pathway. Endocrinology. (2016) 158:en.2016-1097. doi: 10.1210/en.2016-1097

67. Bach LA. Endothelial cells and the IGF system. J Mol Endocrinol. (2014) 54:R1-R13. doi: 10.1530/JME-14-0215

68. Leung DW, Cachianes G, Kuang W-J, Goeddel DV, Ferrara N. Vascular endothelial growth factor is a secreted angiogenic mitogen. Science. (1989) 246:1306-9. doi: 10.1126/science. 2479986

69. Bridges EM, Harris AL. The angiogenic process as a therapeutic target in cancer. Biochem Pharmacol. (2011) 81:118391. doi: 10.1016/j.bcp.2011.02.016

70. Harrison-Woolrych ML, Sharkey AM, Charnock-Jones DS, Smith SK. Localization and quantification of vascular endothelial growth factor messenger ribonucleic acid in human myometrium and leiomyomata. J Clin Endocrinol Metab. (1995) 80:1853-8. doi: 10.1210/jcem.80.6.7775632

71. Gentry CC, Okolo SO, Te Fong LFW, Crow JC, Maclean AB, Perrett CW. Quantification of vascular endothelial growth factor-A in leiomyomas and adjacent myometrium. Clin Sci. (2001) 101:691-5. doi: 10.1042/CS20010096

72. Chen D-C, Liu J-Y, Wu G-J, Ku C-H, Su H-Y, Chen C-H. Serum vascular endothelial growth factor 165 levels and uterine fibroid volume. Acta Obstet Gynecol Scand. (2005) 84:317-21. doi: 10.1080/j.0001-6349.2005.00621.x

73. Tsiligiannis SE, Zaitseva M, Coombs PR, Shekleton P, Olshansky $\mathrm{M}$, Hickey $\mathrm{M}$, et al. Fibroid-associated heavy menstrual bleeding: 
correlation between clinical features, doppler ultrasound assessment of vasculature, and tissue gene expression profiles. Reprod Sci. (2013) 20:361-70. doi: 10.1177/1933719112459233

74. Hoffman PJ, Milliken DB, Gregg LC, Davis RR, Gregg JP. Molecular characterization of uterine fibroids and its implication for underlying mechanisms of pathogenesis. Fertil Steril. (2004) 82:639-49. doi: 10.1016/j.fertnstert.2004.01.047

75. Yu L, Saile K, Swartz CD, He H, Zheng X, Kissling GE, et al. Differential expression of receptor tyrosine kinases (RTKs) and IGF-I pathway activation in human uterine leiomyomas. Mol Med. (2008) 14:26475. doi: 10.2119/2007-00101.YU

76. Hague S, Zhang L, Oehler MK, Manek S, MacKenzie IZ, Bicknell R, et al. Expression of the hypoxically regulated angiogenic factor adrenomedullin correlates with uterine leiomyoma vascular density. Clin Cancer Res. (2000) 6:2808-14.

77. Harris AL. Hypoxia - a key regulatory factor in tumour growth. Nat Rev Cancer. (2002) 2:38-47. doi: 10.1038/nrc704

78. Mayer A, Hockel M, Wree A, Leo C, Horn L-C, Vaupel P. Lack of hypoxic response in uterine leiomyomas despite severe tissue hypoxia. Cancer Res. (2008) 68:4719-26. doi: 10.1158/0008-5472.CAN07-6339

79. Mayer A, Hoeckel M, von Wallbrunn A, Horn LC, Wree A, Vaupel P. HIF-mediated hypoxic response is missing in severely hypoxic uterine leiomyomas. In: Takahashi E, Bruley DF, editors, Oxygen Transport to Tissue XXXI. Boston, MA: Springer US (2010). p. 399-405. doi: 10.1007/978-1-4419-1241-1_58

80. Subramaniam KS, Tapmeier TT, Wang CY, O’Brien D, Philpott M, Manek $\mathrm{S}$, et al. Alternative angiogenesis mechanisms in uterine fibroids related to heavy menstrual bleeding. In: Al-Hendy A, Ku S-Y, editors. Reproductive Sciences. Thousand Oaks, CA: Sage Publications Inc. (2019). p. 226A-7.

81. Buttram VC, Reiter RC. Uterine leiomyomata: etiology, symptomatology, and management. Fertil Steril. (1981) 36:43345. doi: 10.1016/S0015-0282(16)45789-4

82. Di Tommaso S, Massari S, Malvasi A, Bozzetti MP, Tinelli A. Gene expression analysis reveals an angiogenic profile in uterine leiomyoma pseudocapsule. Mol Hum Reprod. (2013) 19:380-7. doi: 10.1093/molehr/ gat007

83. Leppert PC, Al-Hendy A, Baird DD, Bulun S, Catherino W, Dixon D, et al. Summary of the proceedings of the Basic Science of Uterine Fibroids meeting: new developments (February 28, 2020). FeS Sci. (2021) 2:88100. doi: 10.1016/j.xfss.2020.11.001

84. Aleksandrovych V, Pasternak A, Gil K. Telocytes in the architecture of uterine fibroids. Folia Med Cracov. (2019) 59:33-44. doi: 10.24425/fmc.2019.131378

85. Cretoiu SM, Cretoiu D, Marin A, Radu BM, Popescu LM. Telocytes: ultrastructural, immunohistochemical and electrophysiological characteristics in human myometrium. Reproduction. (2013) 145:357-70. doi: 10.1530/REP-12-0369

86. Varga I, Klein M, Urban L, Danihel L, Polak S, Danihel L. Recently discovered interstitial cells "telocytes" as players in the pathogenesis of uterine leiomyomas. Med Hypotheses. (2018) 110:64-7. doi: 10.1016/j.mehy.2017.11.003

87. Schlegel JU. Arteriovenous anastomoses in the endometrium in man. Cells Tissues Organs. (1945) 1:284-325. doi: 10.1159/0001 40175

88. Farrer-Brown G, Beilby JOW, Tarbit MH. The vascular patterns in myomatous uteri. BJOG Int J Obstet Gynaecol. (1970) 77:967-75. doi: 10.1111/j.1471-0528.1970.tb03439.x
89. Bereza T, Tomaszewski KA, Lis GJ, Mizia E, Pasternak A, Mazur M, et al. "Venous lakes" - a corrosion cast scanning electron microscopy study of regular and myomatous human uterine blood vessels. Folia Morphol. (2014) 73:164-8. doi: 10.5603/FM.2014.0024

90. Tomita T, Mah K. Cyclic changes of lymphatic and venous vessels in human endometrium. Open J Pathol. (2014) 04:194205. doi: 10.4236/ojpathology.2014.44025

91. Stewart EA, Nowak RA. Leiomyoma-related bleeding: a classic hypothesis updated for the molecular era. Hum Reprod Update. (1996) 2:295306. doi: 10.1093/humupd/2.4.295

92. Goel S, Duda DG, Xu L, Munn LL, Boucher Y, Fukumura D, et al. Normalization of the vasculature for treatment of cancer and other diseases. Physiol Rev. (2011) 91:1071 LP-121. doi: 10.1152/physrev.00038.2010

93. Jayson GC, Kerbel R, Ellis LM, Harris AL. Antiangiogenic therapy in oncology: current status and future directions. Lancet. (2016) 388:51829. doi: 10.1016/S0140-6736(15)01088-0

94. Carmeliet P, Jain RK. Principles and mechanisms of vessel normalization for cancer and other angiogenic diseases. Nat Rev Drug Discov. (2011) 10:417-27. doi: 10.1038/nrd3455

95. Lasmar RB, Lasmar BP. The role of leiomyomas in the genesis of abnormal uterine bleeding (AUB). Best Pract Res Clin Obstet Gynaecol. (2017) 40:828. doi: 10.1016/j.bpobgyn.2016.09.008

96. Ding L, Xu J, Luo X, Chegini N. Gonadotropin releasing hormone and transforming growth factor $\beta$ activate mitogen-activated protein kinase/extracellularly regulated kinase and differentially regulate fibronectin, type I collagen, and plasminogen activator inhibitor-1 expression in leiomy. J Clin Endocrinol Metab. (2004) 89:5549-57. doi: 10.1210/jc.2004-0161

97. Meng X-M, Nikolic-Paterson DJ, Lan HY. TGF- $\beta$ : the master regulator of fibrosis. Nat Rev Nephrol. (2016) 12:325-38. doi: 10.1038/nrneph.2016.48

98. Yue X, Shan B, Lasky JA. TGF- $\beta$ : titan of lung fibrogenesis. Curr Enzym Inhib. (2010) 6. doi: 10.2174/157340810791233033

99. Sinclair DC, Mastroyannis A, Taylor HS. Leiomyoma simultaneously impair endometrial BMP-2-mediated decidualization and anticoagulant expression through secretion of TGF- $\beta 3$. J Clin Endocrinol Metab. (2011) 96:41221. doi: $10.1210 /$ jc. $2010-1450$

100. Wegienka G, Day Baird D, Cooper T, Woodcroft KJ, Havstad S. Cytokine patterns differ seasonally between women with and without uterine leiomyomata. Am J Reprod Immunol. (2013) 70:327-35. doi: 10.1111/aji.12127

Conflict of Interest: The authors declare that the research was conducted in the absence of any commercial or financial relationships that could be construed as a potential conflict of interest.

Publisher's Note: All claims expressed in this article are solely those of the authors and do not necessarily represent those of their affiliated organizations, or those of the publisher, the editors and the reviewers. Any product that may be evaluated in this article, or claim that may be made by its manufacturer, is not guaranteed or endorsed by the publisher.

Copyright (c) 2022 Uimari, Subramaniam, Vollenhoven and Tapmeier. This is an open-access article distributed under the terms of the Creative Commons Attribution License (CC BY). The use, distribution or reproduction in other forums is permitted, provided the original author(s) and the copyright owner(s) are credited and that the original publication in this journal is cited, in accordance with accepted academic practice. No use, distribution or reproduction is permitted which does not comply with these terms. 